\title{
Functional Analysis of the Type III Effectors AvrRpt2 and AvrRpm1 of Pseudomonas syringae with the Use of a Single-Copy Genomic Integration System
}

\author{
David S. Guttman and Jean T. Greenberg \\ Department of Molecular Genetics and Cell Biology, The University of Chicago, 1103 E. 57th Street, \\ EBC410, Chicago 60637, U.S.A. \\ Accepted 13 October 2000.
}

\begin{abstract}
Gram-negative phytopathogenic bacteria require a type III secretion apparatus for pathogenesis, presumably to deliver Avr effector proteins directly into plant cells. To extend previous studies of Avr effectors that employed plasmids encoding Avr proteins, we developed a system that permits the integration of any gene into the Pseudomonas syringae genome in single copy. With this system, we confirmed earlier findings showing that $P$. syringae $\mathrm{pv}$. maculicola strain PsmES4326 expressing the AvrRpt2 effector induces a resistance response in plants with the cognate $R$ gene, RPS2. Chromosomally located avrRpt2, however, provoked a stronger resistance response than that observed with plasmid-expressed AvrRpt 2 in $\mathrm{RPS}^{+}$ plants. Additionally, chromosomal expression of AvrRpt2 conferred a fitness advantage on $P$. syringae grown in $r p s 2$ plants, aiding in growth within leaves and escape to leaf surfaces that was difficult to detect with plasmid-borne avrRpt2. Finally, with the use of the genomic integration system, we found that a chimeric protein composed of the $\mathrm{N}$ terminus of the heterologous AvrRpm1 effector and the C-terminal effector region of AvrRpt2 was delivered to plant cells. Because the $C$ terminus of AvrRpt 2 cannot translocate into plant cells on its own, this indicates that the N-terminal region can direct secretion and translocation during an infection, which supports the view that Avr proteins have a modular design. This work establishes a readily manipulatable system to study type III effectors in a biologically realistic context.
\end{abstract}

Additional keywords: hrp-hrc, hypersensitive response, transmission, virulence.

Gram-negative plant pathogenic bacteria secrete a broad range of elicitors that can induce defenses in a host if it bears the appropriate cognate resistance $(R)$ gene (Bonas and Van den Ackerveken 1999). This resistance response is characterized by a rapid programmed cell death called the hypersensi-

Corresponding author: J. Greenberg; Telephone: +1-773-834-1908 Fax: +1-773-702-9270; E-mail: jgreenbe@ midway.uchicago.edu

Current address of D. S. Guttman: Department of Botany, University of Toronto, 25 Willcocks Street, Toronto, Ontario, M5S 3B2, Canada; E-mail: guttman@botany.utoronto.ca tive response (HR) (Greenberg 1997). A subset of bacterial elicitors are proteins called effectors that are secreted through a multisubunit complex called the type III secretion apparatus (Bonas and Van den Ackerveken 1999). This apparatus is encoded by the $h r p-h r c$ pathogenicity island and shares substantial homology with the type III secretory apparatus bacterial pathogens of animals (Fenselau et al. 1992; Gough et al. 1992; Van Gijsegem et al. 1993; Van Gijsegem et al. 1994) and the flagellar motor (Van Gijsegem et al. 1995).

The best-studied type III effectors are produced by animal pathogenic bacteria of the genus Yersinia spp., which is closely related to many phytopathogens. The $\mathrm{N}$ termini of type III secreted effectors, called Yops, are sufficient to direct their secretion and translocation into the host cell (Sory and Cornelis 1994; Sory et al. 1995). In some cases, only a region encoded in the $5^{\prime}$ mRNA is needed to direct Yops into the extracellular medium (Anderson and Schneewind 1997). Similar 5' mRNA signals are likely to be involved in hrp-hrcdependent secretion of phytopathogenic Avr effector proteins into the extracellular medium (Anderson et al. 1999). In the case of YopE, additional amino acid sequences are needed for the translocation of the protein into host cells (Sory et al. 1995).

Whereas Avr proteins have been shown to secrete into the extracellular medium in vitro (Alfano and Collmer 1997; Mudgett and Staskawicz 1999; Pirhonen et al. 1996), translocation into plant cells has not been demonstrated directly. Nonetheless, it is likely that at least some Avr effectors are translocated into plant cells because their direct expression in plant cells confers $R$-gene-specific cell death (De Feyter et al. 1998; Gopalan et al. 1996; Leister et al. 1996; Rate et al. 1999; Scofield et al. 1996; Stevens et al. 1998; Tang et al. 1996; Van den Ackerveken et al. 1996). Currently, it is not known which nucleic acid and/or protein sequences are required for secretion and translocation of Avr effectors into plant cells. Mudgett and Staskawicz (1999) demonstrated that N-terminal deletions of the Pseudomonas syringae AvrRpt2 effector disrupt secretion into the medium and delivery to plant cells. Although these studies raise the possibility that Avr and Yop proteins reach the host cytoplasm by similar mechanisms, the demonstration of N-terminal sufficiency for secretion and translocation into plant cells or the demonstration that Avr proteins are translocated directly into host cells via the $h r p$ secretory system is lacking. 
In addition to triggering a defense response in plants, some Avr proteins enhance virulence when expressed in bacteria infecting plants that lack the cognate $R$ gene (Gabriel 1999). Enhanced growth of bacteria carrying effectors has been demonstrated in P. syringae (Jackson et al. 1999; Ritter and Dangl 1995) and Xanthomonas campestris (Kearney and Staskawicz 1990). Yang and colleagues (1994) took the analysis one step further by determining that the $X$. campestris avrb6 gene enabled the bacterium to dramatically increase disease symptoms on its host (water soaking), thereby releasing more bacteria to the surface of the leaf, yet they were unable to show that the gene conferred a direct growth benefit.

The study of type III phytopathogenic virulence mechanisms is hampered partially by the use of plasmids and cosmids to express bacterial genes. The loss of extrachromosomal elements during in planta growth is an especially difficult problem because it is usually impossible to select for the maintenance of the plasmid or cosmid vectors (Abebe et al. 1997). A recent example of the problems associated with plasmid loss was illustrated by Hendrickson and colleagues (2000). They found that an rpoN mutant of $P$. syringae pv. maculicola (PsmES4326) was unable to maintain a clone containing the $h r p L$ gene during pathogen infection of Arabidopsis spp. Additionally, typical broad-host-range vectors are often large and difficult to manipulate experimentally. A further problem with the use of plasmids is the potential for nonphysiological levels of protein accumulation as a result of altered or variable gene dosage. To circumvent these problems, we developed a single-copy chromosomal integration system that greatly facilitates the rapid analysis of the function and structure of $P$. syringae Avr effectors in a biologically realistic manner. With this system, we report that two avr genes, avrRpt2 and avrRpm1, can induce resistance responses in heterologous strains of $P$. syringae when present in single copy. These responses are stronger than those elicited by strains with plasmid-borne copies of these genes. We also find that the AvrRpt 2 effector increases the fitness of $P$. syringae grown in host plants lacking the cognate resistance protein Rps2. Finally, we show that N-terminal deletions of AvrRpt2 defective for secretion and translocation can be delivered to plant cells by the $\mathrm{N}$ terminus of a heterologous Avr protein. This suggests that Avr proteins possess a modular structure and that the $\mathrm{N}$ terminus of Avr proteins shows the expected role in secretion and translocation in a biologically realistic assay. This work demonstrates that single-copy chromosomal integration offers a powerful and rapid way to dissect the functional regions of effectors and address their biological role in disease.

\section{RESULTS}

The $P$. syringae pv. tomato avrRpt 2 gene functions in single copy when expressed from the chromosome of a heterologous $P$. syringae strain.

avrRpt 2 was originally cloned from a $P$. syringae pv. tomato (PtoJL1065) genomic cosmid library (Dong et al. 1991; Whalen et al. 1991) and is a genomic, single-copy locus (Innes et al. 1993). We wanted to introduce avrRpt 2 and derivative constructs stably into $P$. syringae strains that do not naturally possess the gene in single copy in order to study its function and structure in a biologically realistic manner, which would alleviate problems associated with the use of plasmids. We created a "suicide" integration vector (Fig. 1) that contained a 527-bp internal fragment of the $P$. syringae pv. maculicola (strain PsmES4326) recA gene, which is dispensable for $P$. syringae virulence (Willis et al. 1988), as well as a kanamycin resistance marker, but no $P$. syringae origin of replication. After the integration vector was introduced into $P$. syringae by a single reciprocal homologous recombination event (Campbell integration, Fig. 1), the resulting strains were completely stable during in vitro and in planta growth and possessed a single copy of the vector integrated at the recA locus, as assayed by Southern blot analysis (data not shown). In contrast, when strains carrying the broad-host vector pLAFR3 were inoculated into plants, 20 to $45 \%$ of bacteria lost the vector after 4 days of growth in planta. PsmDG3 (PsmES4326 recA $\Omega$ pCKTR) grew as well as the parent strain PsmES4326 lacking the vector (Fig. 2) and showed the same level of disease symptoms (data not shown).

To test whether single-copy expression of an avr gene would yield the same results as found in earlier studies of plasmid-borne $a v r$ genes expressed in heterologous strains,
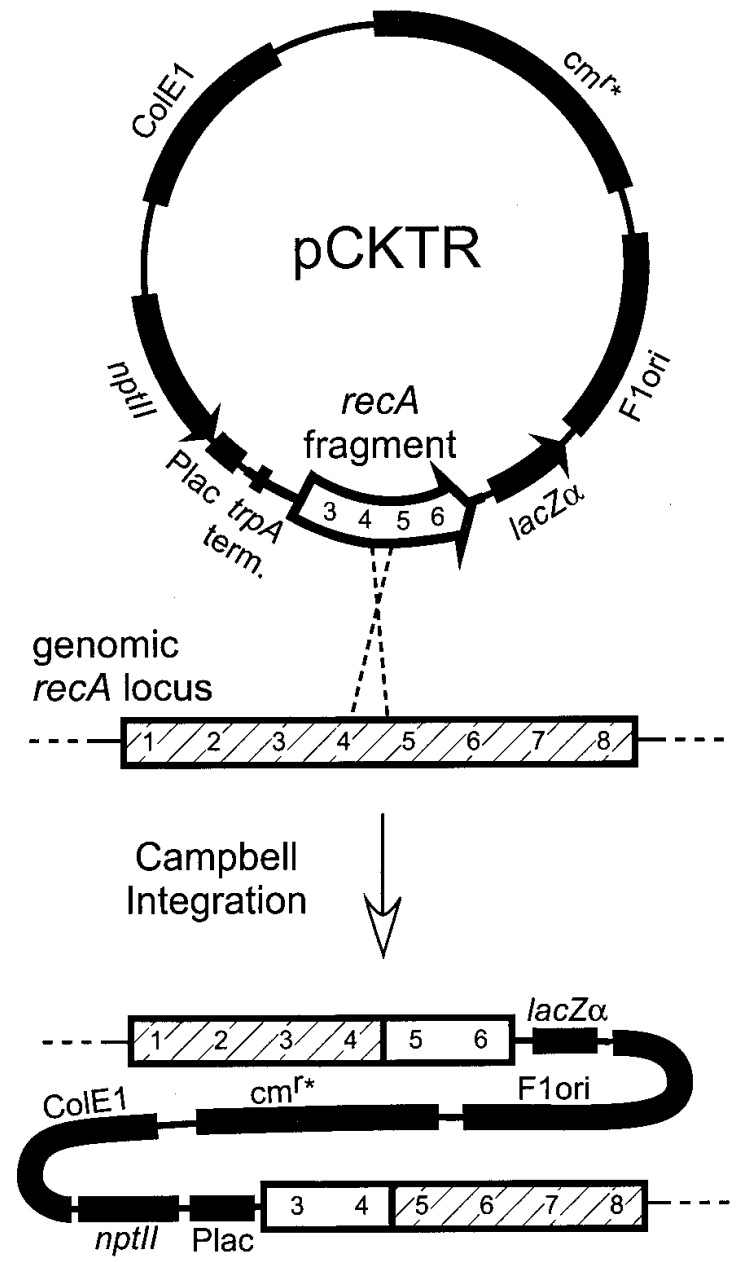

Fig. 1. Integration vector and Campbell integration strategy. At top is a schematic of the integration vector pCKTR. Bottom shows a schematic of the chromosomal structure of pCKTR integrated into the chromosomal locus of recA. The recA locus is numbered 1 to 8 arbitrarily to represent positions within the gene. Chloramphenicol resistance $\left(\mathrm{cm}^{\mathrm{r}}\right)$ is nonfunctional in pCKTR. 
we cloned the avrRpt 2 gene into the integration vector and introduced it into PsmES4326. Host recognition was retained in the PsmDG6 (recASavrRpt2) strain. We compared the growth of PsmES4326 carrying avrRpt2, either integrated into the genome or plasmid-borne, in Arabidopsis spp. expressing the RPS2 resistance gene product required for AvrRpt2 recognition. PsmES4326-(pLAFR::avrRpt2) and PsmDG6 (recA $\Omega$ avrRpt2) showed reduced growth relative to the congenic virulent $P$. syringae strains lacking avrRpt2 (Fig. 2). Surprisingly, although PsmDG6 and PsmES4326-(pLAFR::avrRpt2) were avirulent on RPS2 ${ }^{+}$ Arabidopsis spp., the integrated version induced a stronger HR than the plasmid-borne version, as evidenced by the enhanced tissue collapse of the PsmDG6-infected tissue (Fig. 3A; note the wrinkling of the leaf tissue infected with PsmDG6), enhanced ion leakage from PsmDG6-infected tissue (Fig. 4), and reduced growth of PsmDG6 relative to PsmES4326-(pLAFR::avrRpt2) (Fig. 2). Although the HR with PsmDG6 was stronger than that found with PsmES4326 carrying avrRpt 2 on a plasmid, the timing of HR initiation was not obviously different (data not shown). We detected a similar increase in the strength of the HR for integrated versus plasmid-borne avrRpt 2 when avrRpt 2 was introduced into random sites in the genome by a transposon (data not shown). The plant resistance response provoked by PsmES4326 harboring integrated avrRpml also was stronger than that found with plasmid-borne avrRpml (data not shown). These results show that recognition of avirulent $P$. syringae is retained when the avr genes are expressed in single copy in a heterologous strain. Furthermore, the effects of $a v r$ genes on bacterial recognition are enhanced when the genes are chromosomal compared with plasmidborne. We have not explored the molecular basis for the observed differences. These experiments show that the use of plasmid-borne $a v r$ genes can underrepresent the effects they have on pathogen recognition.

\section{AvrRpt2 is a virulence factor in $r p s 2^{-}$plants.}

Some $a v r$ genes enhance the virulence of bacterial phytopathogens (Jackson et al. 1999; Kearney and Staskawicz 1990; Ritter and Dangl 1995; Yang et al. 1994). Having shown that avrRpt 2 provokes a resistance response in single copy, we tested for a possible virulence role in plants lacking the cognate RPS2 gene. Previously, we found that growth of PsmES4326 carrying plasmid-borne avrRpt2 showed some plasmid loss over the time course of the experiment (data not shown), making it difficult to definitively assess the potential virulence function of this gene. Additionally, the strain from which avrRpt 2 was isolated was recalcitrant to transformation (data not shown), precluding the functional analysis of AvrRpt 2 by the creation of loss of a function mutant. To cir-


to assess the potential virulence function of AvrRpt2. Bacteria were inoculated at a low titer of optical density (OD) at 600 $\mathrm{nm}$ of 0.0002 into plants lacking the RPS2-mediated recognition of AvrRpt2 (rps2-101c). Leaves were washed extensively immediately after infection so that no $P$. syringae cells were detected on leaf surfaces of the majority of leaves at the beginning of the experiment. We monitored bacterial density in three ways over a period of 6 days. First we washed the leaves and titered the bacteria in the wash solution to assess the number of bacteria living on the surface, a measure of the transmission potential of the bacteria. Second, we surface sterilized the leaf and took a leaf punch from the most highly symptomatic area of the leaf. Finally, we assayed the remainder of the leaf for bacterial load. Leaves of similar sizes were sampled at each time point (Fig. 3B; unpaired $t$ test of leaf area; $P=0.750$ ). Figure 3B shows leaves sampled from rps2$101 c$ plants infected with PsmDG3 (integration control) or PsmDG6 (integrated avrRpt2) after 6 days. A quantitative analysis of the percentage of healthy green tissue remaining after infection showed that PsmDG3 had 50.5\% (standard error $[\mathrm{SE}]=14 \%)$, whereas PsmDG6 had $11.6 \%$ (SE = $13.3 \%)$ green tissue. These values were significantly different $(P<0.0001$; unpaired $t$ test; $n=24)$. Thus, disease symptoms (overall yellowing) were stronger on rps 2 plants inoculated with the avrRpt2-containing strain than the control.

Growth experiments confirmed that the presence of avrRpt 2 (PsmDG6) allowed the bacteria to significantly increase their density by all three measures (Fig. 5). The presence of avrRpt 2 provided the greatest benefit during the first couple of days of infection, allowing the bacteria to more rapidly increase in density than those bacteria without the avr gene. This difference was maintained throughout the course of the infection. No significant growth difference was observed between these strains grown in either rich or minimal media in vitro (data not shown). Interestingly, bacteria carrying avrRpt2 appeared on leaf surfaces in greater numbers than bacteria lacking avrRpt2 (Fig. 5A), indicating a role for AvrRpt 2 in aiding bacterial transmission. PsmDG6 did not grow better than PsmDG3 when inoculated directly on leaf surfaces (data not shown).

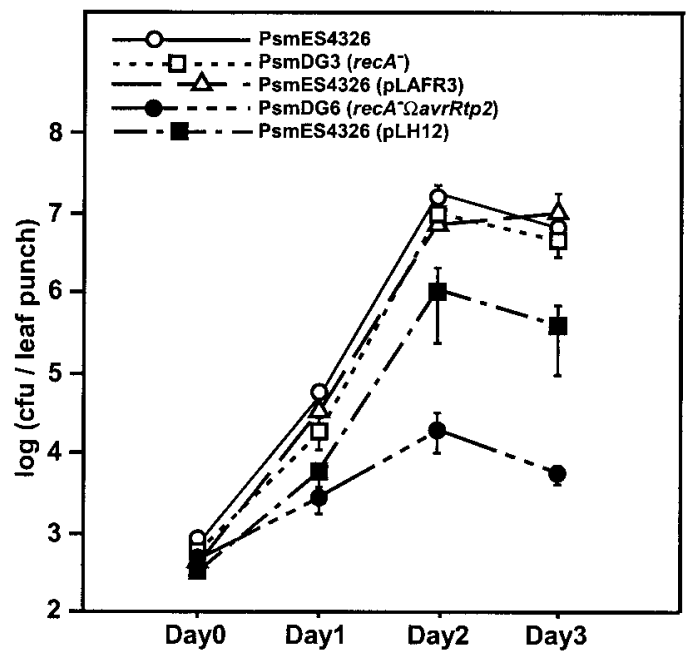

Fig. 2. Bacterial growth assay. Bacteria were inoculated into Arabidopsis thaliana with an RPS2 ${ }^{+}$background at an optical density of $600 \mathrm{~nm}$ at 0.002 . PsmES4326 is the wild-type strain. PsmDG3 has a control vector integrated into the recA locus. PsmES4326 (pLAFR3) carries the broad-host-range cosmid pLAFR3. PsmDG6 has the avrRpt 2 containing vector integrated into the recA locus. PsmES4326 (pLH12) carries the avrRpt 2 gene on pLAFR3. Four replicate leaves were taken for each point. Error bars represent one standard error on each side of the mean. The experiment was replicated twice. Growth of PsmES4326 carrying pLH12 was significantly lower than PsmDG3 or PsmES4326 carrying pLAFR3 ( $P<0.05$ on days 2 and 3; unpaired $t$ tests). Growth of PsmDG6 was significantly different from all other strains on days 2 and 3 ( $P<0.02$; unpaired $t$ tests). 
Avr proteins have modular regions required for their function in the host environment.

Previously, Mudgett and Staskawicz (1999) established that the effector region of AvrRpt2, required for RPS2-mediated recognition, resided between amino acids 120 to 255 in the Cterminal portion of the protein. We confirmed these findings independently with a transient expression system that relies on biolistic transformation of plant cells (data not shown). Deletion of sequences encoding the first 9 to 119 amino acids was previously shown to abolish secretion and translocation with-


out affecting the AvrRpt 2 protein accumulation in $P$. syringae (Mudgett and Staskawicz 1999). This suggests that a secretion and translocation signal might reside in the $\mathrm{N}$-terminal region of AvrRpt2. Recently, Anderson and colleagues (1999) showed that the $5^{\prime}$ mRNA regions encoded by several phytopathogenic effector genes were sufficient for the secretion of a reporter protein from bacteria into the extracellular medium. Collectively, these experiments support the notion that Avr proteins are modular with respect to secretion, although it has not yet been addressed whether the $5^{\prime}$ mRNAs or additional sequences are sufficient for the secretion and/or translocation of phytopathogenic effector proteins expressed during a hostpathogen interaction. This is an important consideration because in the Yersinia spp. YopE effector, different signals are required for in vitro secretion and in vivo translocation into animal cells (Cheng et al. 1997).

We tested our single-copy genomic expression system for its utility to further establish the modular structure of Avr effectors when they function in the context of host-pathogen interactions. This system allowed for the rapid construction of Avr chimeras because the integration vector was experimentally easier to manipulate than the available broad-host-range vectors as a result of its relatively small size. We made chimeras encoding the $\mathrm{C}$ terminus of AvrRpt 2 and the $\mathrm{N}$ terminus of another Avr protein, AvrRpm1. Three chimeras were constructed: pDSG7 encodes a fusion of the first 43 amino acids of AvrRpm1 to the C-terminal 214 amino acid of AvrRpt2 expressed under the control of the AvrRpm1 promoter; pDSG8, which encodes a fusion of the first 43 amino acids of AvrRpm1 to the C-terminal 176 amino acids of AvrRpt2 under

\section{$\leftarrow$}

Fig. 3. Hypersensitive response (HR) induction by bacteria harboring avrRpt2. A, HR assay of Pseudomonas syringae strains carrying the control vector (left), avrRpt2 carried on the low-copy-number cosmid pLAFR3 (center), or single-copy integrated avrRpt2 (right). Half leaves (inoculated side is indicated with a white dot) were inoculated at optical density (OD) of $600 \mathrm{~nm}$ at 0.01 and photographed after $24 \mathrm{~h}$. Recognition of the AvrRpt2 protein by plants producing the resistance protein RPS2 resulted in an HR (cell death). Leaves infected by the control strain with the suicide vector integrated at the recA locus (PsmGD3) looked identical to the strain carrying the empty vector (no avr gene, data not shown). This experiment was repeated four times. B, Effect of AvrRpt 2 on virulence in rps 2 plants. Congenic strains derived from PsmES4326, which differed only by the presence or absence of avrRpt 2 integrated in single copy into the genome, were inoculated at $\mathrm{OD}_{600}$ at 0.0002 into Arabidopsis lacking the RPS2 resistance gene. Plants were photographed after 6 days. The strain carrying the avrRpt2 gene (PsmDG6) produced noticeably more disease symptoms than the strain lacking avrRpt2 (PsmDG3). C, HR test of AvrRpt2 and AvrRpm1::AvrRpt2 chimeric protein. The chimera is the native promoter, and the first 43 amino acids of AvrRpm1 fused to AvrRpt 2 harboring a 79 amino acid deletion of its $\mathrm{N}$ terminus. PsmES4326 strains carrying either a plasmid-borne copy of avrRpt2 or an integrated single copy of the AvrRpm1::AvrRpt2 chimera were inoculated at $\mathrm{OD}_{600}$ at 0.01 into one half of an Arabidopsis leaf (side inoculated is indicated with a white dot). In some cases, the leaf half that was inoculated showed such a severe HR that the whole side of the leaf was crushed against the uninoculated leaf half. The plant genotypes are presented above the leaves. Rps2 is the cognate resistance protein to AvrRpt2. Rpm1 is the cognate resistance protein to AvrRpm1. The same plant genotypes inoculated with control strains lacking the indicated avr genes or avr fusion genes showed no HR on the plants (data not shown). Additionally, PsmES4326 with full length avrRpml integrated at the recA locus did not induce the HR on $R P S 2^{+}-r p m 1^{-}$plants (data not shown). This experiment was repeated three times. 
the control of the AvrRpm1 promoter; and pDSG9, which encodes a fusion of the first 89 amino acids of AvrRpm1 to the C-terminal 214 amino acids of AvrRpt 2 under the control of the AvrRpm1 promoter. These constructs were integrated into PsmES4326 and used for infection experiments.

All three chimeras were capable of eliciting RPS2dependent resistance responses, as evidenced by the decreased growth of the pathogens carrying these fusions (Fig. 6) and RPS2-dependent-RPM1-independent HR (Fig. 3C). The control strain bearing full-length avrRpml, however, showed an $\mathrm{HR}$ only on $R P M 1^{+}$plants (data not shown). No decrease in growth was found in infections of $R P M 1^{+} r p s 2^{-}$plants, except with the control strain (PsmDG34) bearing full-length integrated avrRpml (Fig. 6). This indicates that the specificity of AvrRpt 2 was retained in the chimeras. Thus, the avrRpmlencoded $\mathrm{N}$-terminal 45 amino acids fused to the $\mathrm{C}$ terminus of AvrRpt 2 reversed the $\mathrm{HR}^{-}$phenotype, previously reported for the truncated AvrRpt2 protein (Mudgett and Staskawicz 1999), which suggests that the $\mathrm{N}$ terminus of AvrRpm1 delivered the $\mathrm{C}$ terminus of AvrRpt2 to the cell surface and likely mediated its translocation into the plant cell where AvrRpt2 functions (Leister et al. 1996).

Mudgett and Staskawicz (1999) reported that N-terminal deletions of AvrRpt2 missing up to 119 amino acids were synthesized and stable in $P$. syringae. We could not detect AvrRpt 2 protein by immunoblot analysis, however, in any of our avrRpt $2 \mathrm{~N}$-terminal deletion constructs (even those deleting as few as three amino acids after the start methionine) in PsmES4326 (data not shown). Therefore, we could not independently verify that the $\mathrm{HR}^{-}$and secretion-translocation deficiency phenotypes of $P$. syringae carrying similar deletion constructs of avrRpt2 to those previously reported (Mudgett and Staskawicz 1999) were not simply a result of the lack of the protein. The deletion constructs reported by Mudgett and Staskawicz (1999) were driven by the heterologous nptII promoter, whereas our constructs retained the native avrRpt2 promoter. Because truncated AvrRpt 2 protein can accumulate in $P$. syringae, the lack of truncated AvrRpt 2 accumulation in our strains with the native avrRpt 2 promoter was likely a result of the disruption of a $5^{\prime}$ uncharacterized regulatory element, possibly encoded in mRNA (Anderson et al. 1999). This element appears to require the native promoter in order to have an influence on AvrRpt2 production.

\section{DISCUSSION}

This study demonstrates the advantages of the use of singlecopy chromosomal integrations at the recA locus for functional and structural studies of the AvrRpt 2 and AvrRpm1 effectors of $P$. syringae, from which three major conclusions can be drawn. First, we found that avrRpt 2 and avrRpml can function in single copy and induce resistance responses that were stronger than those evoked by the same strains bearing plasmid-borne $a v r$ genes. Second, we demonstrated that AvrRpt 2 is involved in virulence (the ability to cause disease symptoms in the host), in planta growth, and transmission in the $P$. syringae infections of $r p s 2^{-}$plants. These functions were difficult to demonstrate with a plasmid-borne copy of the gene, probably as a result of variable gene doses and/or plasmid stability during the low-dose infections (our unpublished observations). Finally, we showed that C-terminal regions of AvrRpt 2 could be delivered to plant cells when fused to the $\mathrm{N}$ terminus of AvrRpm1, suggesting modular structures for Avr proteins required for their function during host-pathogen interactions. The cloning and integration of the $a v r$ chimeras was greatly facilitated by the use of the genomic integration vector, which is smaller and easier to manipulate than most broad-host-range vectors currently in use.

The integration vector used in this study is broadly useful for expressing genes in Pseudomonas spp. We have successfully performed integrations in P. syringae pathovars maculicola, phaseolicola, and tomato. Additionally, the high conservation of the recA locus between Pseudomonas spp. allows the integration of our constructs into P. aeruginosa (L. Rahme, personal communication). While we could not detect any pathogen fitness cost for $P$. syringae $p v$. maculicola having constructs integrated at the recA locus, it is possible that such a cost would occur for bacteria growing under field conditions. This would have to be specifically tested by researchers interested in using this method to achieve heterologous expression of virulence genes. If $r e c A$ integrants showed decreased fitness in the field, however, it should be possible to

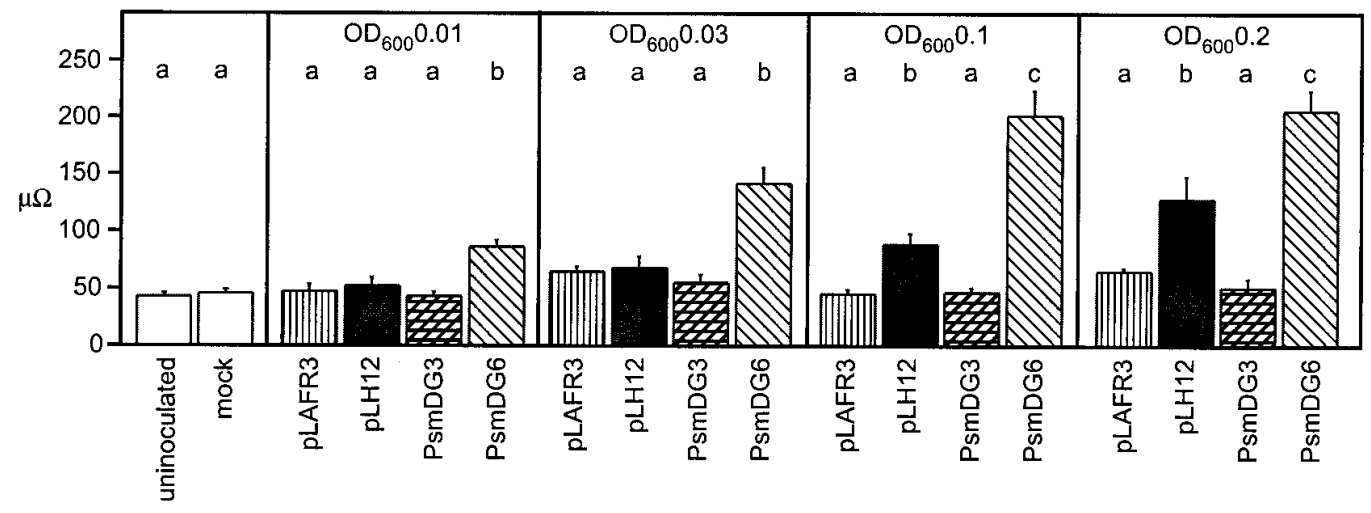

Fig. 4. Ion leakage from Pseudomonas syringae-infected tissue. Indicated strains were inoculated into plants. Fifteen hours later, the tissue was assayed for ion leakage with conductivity measurements. Four samples were used for each measurement. Bars indicate standard error of the mean. Letters above each bar represent significance groups as determined by Fisher's protected least significant difference measure (a post-hoc multiple $t$ test). Each letter group differs from the other letter groups at a level of $P<0.05$ or better. Each test was performed only within an inoculation dose. This experiment was repeated twice with similar results. 
modify the targeting locus and use double recombinants to achieve chromosomal insertions that are similarly useful to the ones documented in this study.

One surprising outcome of this study is that AvrRpt2 induced a stronger host defense response, as evidenced by greater tissue collapse, greater ion leakage, and less pathogen


Fig. 5. Bacterial growth assay of the virulence advantage conferred by AvrRpt2. Bacteria harboring either an integrated avrRpt2 (PsmDG6) or a control vector (PsmDG3) were inoculated into rps2 plants. Three measures of bacterial growth were taken each day. A, Leaves were first washed to collect and measure the bacteria growing on the leaf surface. B, A fixed-diameter leaf punch was taken from the most highly infected region of the leaf. $\mathbf{C}$, Remainder of the leaf was homogenized to determine total bacterial load. Twelve replicates were taken at each time point for each strain. The experiment was repeated three times. Error bars represent one standard error above and below the mean. Results of unpaired $t$ tests are presented below each data point. $P=0.05>*>0.01$ $>* *>0.001$ growth when the avrRpt 2 gene was integrated in single copy. We do not believe that the loss of recA as a result of the integration of the vector is a significant factor because we observed similar results when we introduced avrRpt 2 into random genomic locations with a transposon (our unpublished observations). It is possible that AvrRpt 2 is overproduced from the multicopy cosmid and that the protein excess blocks the secretion apparatus and, as a result, inhibits translocation into the plant cell. It also is possible that the plasmid is lost at a low rate when the bacteria are grown in the plant, which would result only in a proportion of the infecting bacteria being able to induce the host defenses. In support of this possibility, we found that the extrachromosomal vector pLAFR3 has a loss rate of 20 to $45 \%$ from PsmES4326 after 4 days of

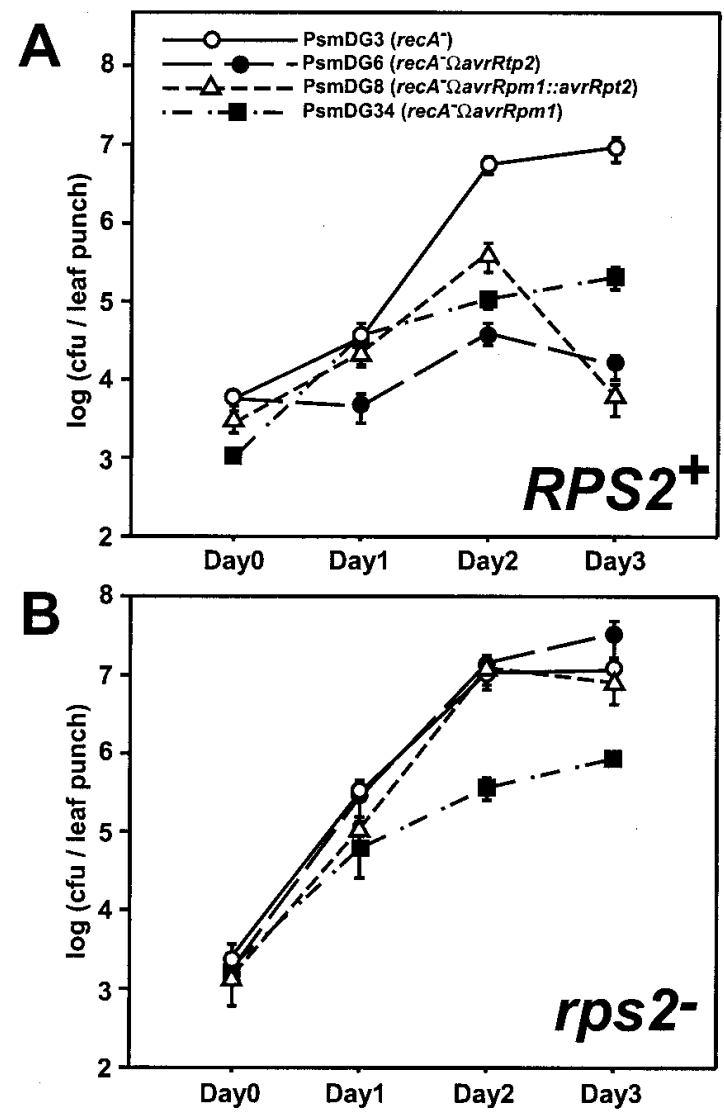

Fig. 6. Bacterial growth assays: AvrRpm1::AvrRpt2 chimeric protein function. Growth of bacteria containing either an integrated control vector (PsmDG3), integrated copy of avrRpt2 (PsmDG6), integrated copy of avrRpm1 (PsmDG34), or integrated copy of the avrRpm1::avrRpt2 chimeric gene (PsmDG8, composed of the native avrRpm1 promoter, and the first 43 amino acids of AvrRpm1 fused to a 79 amino acid N-terminal deletion of AvrRpt2) was measured on two plant genotypes. A, RPS2+ $2^{+} P M 1^{+}$: Growth of all the strains was significantly different from PsmDG3 on days 2 and $3(P<0.02$; unpaired $t$ tests). B, rps $2^{-}-R P M 1^{+}$: Growth of strains PsmDG3, PsmDG6, and PsmDG8 was not significantly different, although of strain PsmDG3 was significantly different from all other strains on days 2 and $3(P<0.05$ on days 2 and 3, except for day 3 with strain PsmDG8, which had a $P$ value of 0.06; unpaired $t$ tests). RPS2 is cognate resistance protein to AvrRpt2. RPM1 is the cognate resistance protein of AvrRpm1. Bacteria were inoculated at optical density of $600 \mathrm{~nm}$ at 0.002 . Eight replicates were taken at each time point, and the experiment was repeated three times. The error bars represent one standard error above and below the mean. 
growth of the bacteria in planta, whereas the recA integrated vector is completely stable.

The virulence and growth function of AvrRpt2 in rps2plants add to the growing number of type III effectors that increase bacterial fitness in plants lacking the cognate $R$ genes (Gabriel 1999). Although the growth advantage conferred by AvrRpt 2 was modest, even small differences in growth would confer a significant fitness advantage over pathogens lacking the gene. The leaf-wash experiments showed that bacteria carrying avrRpt 2 were more prevalent on leaf surfaces than the bacteria lacking the gene, indicating a role for AvrRpt 2 in enhancing transmission. Because no bacteria were detected on the majority of leaf surfaces at the beginning of the experiment, any bacteria that were found there at subsequent times must have been released from the apoplast of the plant cells in the infected tissue. We envision at least two ways that AvrRpt 2 might aid in allowing greater recovery of bacteria from plant surfaces after infection. First, bacteria carrying avrRpt 2 may be released earlier or in greater numbers onto leaf surfaces than bacteria lacking the gene. In a second scenario, bacteria harboring avrRpt 2 may be released at the same rate as bacteria lacking avrRpt2. Subsequent to release, AvrRpt2 might confer a fitness advantage, resulting in a greater growth rate of the bacteria on leaf surfaces. A combination of the two scenarios also may occur. Our data does not allow us to distinguish between a role for avrRpt2, specifically in release of bacteria, or in epiphytic growth once bacteria reach the leaf surface. Epiphytic-growth experiments in which bacteria were inoculated only on leaf surfaces, however, indicated that bacteria carrying avrRpt 2 grew the same or slightly worse than the control strain lacking the gene (our unpublished observations).

Similar evidence for increased in planta growth of $P$. syringae carrying avrRpt 2 comes from studies of $P$. syringae pv. tomato strain DC3000 carrying avrRpt2 gene on a plasmid. $r p s 2^{-}$plants in the relatively $P$. syringae-tolerant Nossen ecotype and mutants of the Col ecotype with constitutive disease resistance showed enhanced susceptibility to $P$. syringae carrying avrRpt2 (Chen et al. 2000). A virulence effect was not discernible in the $P$. syringae-susceptible Col ecotype, however, unless avrRpt 2 was expressed directly inside the plant cells. This may be a result of variable gene doses of avrRpt 2 or plasmid loss from $P$. syringae during the growth studies. These authors did not examine a role for AvrRpt2 in transmission. The fact that avrRpt 2 conferred a fitness advantage in the context of two different $P$. syringae pathovars suggests that a virulence function for AvrRpt 2 is biologically meaningful and not an artifact of expression in strain PsmES4326. The definitive assessment for its role in the strain in which it was discovered (PtoJL1065) (Dong et al. 1991; Whalen et al. 1991), however, would require a gene knockout in that strain. Unfortunately, our efforts to transform PtoJL1065 have not been successful.

How might AvrRpt2 function to enhance virulence? One possibility is that it acts directly on a plant target to compromise the induction or execution of plant defenses. A second possibility is that plant defenses are not compromised, but AvrRpt 2 stimulates a plant response that counteracts the effects of the other defenses. For example, AvrRpt 2 might cause the release of needed nutrients from the plant into the apoplasm by binding to and altering membrane permeability or ion channels. Another possibility is that AvrRpt2 acts indirectly by allowing bacteria to increase the levels or activities of other virulence factors such as other effectors or toxins. A combination of these mechanisms also is possible. The fact that plants producing AvrRpt 2 can enhance the virulence of $P$. syringae pv. tomato (Chen et al. 2000) suggests that its effects probably are exerted in the plant and not through enhanced activation of other virulence factors. An effect of AvrRpt 2 on the levels of known virulence factors, however, has not yet been explored. Interestingly, some accessions of Arabidopsis spp. naturally lacking RPS2 do not show enhanced disease when infected with PsmES4326 carrying avrRpt2, suggesting that there is genetic variability of the plant-host target(s) of AvrRpt 2 that could be exploited to identify the molecular nature of the target(s) (B. A. Vinatzer and J. T. Greenberg, unpublished observations).

Structure-function analysis of phytopathogenic effectors shows that an mRNA sequence encoded in the $5^{\prime}$ end of several genes is sufficient to mediate secretion into a heterologous protein medium, similar to effectors from animal pathogens (Anderson and Schneewind 1997; Anderson et al. 1999). Deletion experiments have localized the $R$-gene-mediated recognition of AvrRpt2 to the C-terminal portion of the protein (Mudgett and Staskawicz 1999). Our results show that the AvrRpm1 N terminus can complement a secretiontranslocation-defective C-terminal region of AvrRpt2 and restore the ability of AvrRpt 2 to activate an $R$-gene-specific resistance response. This finding further supports the notion that effector functions are encoded in contiguous stretches of primary sequence that comprise functional modules. Importantly, our results support the view that one of those separable modules functions to deliver effectors to the plant cell rather than only to the extracellular medium, as demonstrated in in vitro studies (Anderson et al. 1999). It has not been shown conclusively that phytopathogenic effectors are directly translocated into plant cells, although the fact that AvrRpt 2 and AvrRpm1, when expressed inside plant cells, act in an $R$-genespecific manner (Leister et al. 1996; Rate et al. 1999) strongly suggests that they are directly translocated. Thus, it is likely that the $\mathrm{N}$ terminus of AvrRpm1 encodes a sequence that is sufficient for translocation of the C-terminal effector module of AvrRpt2.

The N-terminal region of AvrRpm1 as well as several other effectors harbors myristoylation and palmitoylation sites (Nimchuk et al. 2000). Myristoylation is important for optimal function and localization of AvrRpm1 to the host plasma membrane (Nimchuk et al. 2000). The fact that the $\mathrm{N}$ terminus of AvrRpm1 could restore to the plant delivery of the secretion-translocation-deficient C-terminal region of AvrRpt2 suggests that AvrRpt 2 may function when tethered to the membrane. It is unlikely, however, that AvrRpt2 is normally anchored to the membrane in this way. Although AvrRpt 2 has a possible myristoylation site at amino acid 121 , the protein is not processed in a manner likely to expose the myristoylation site for binding to the membrane (Mudgett and Staskawicz 1999). It is more likely, therefore, that if AvrRpt 2 localizes to the membrane, it does so via interactions with a membraneassociated protein. Alternatively, AvrRpt 2 might not normally localize to the membrane. Note that not all of the AvrRpm1 protein localizes to the membrane in planta and thus the chimeras between AvrRpm1 and AvrRpt2 may have membrane 
and nonmembrane locations. In support of this possibility, we found that strains bearing any of several reciprocal chimeras in which the $\mathrm{N}$ terminus of AvrRpt 2 was fused to the $\mathrm{C}$ terminus of AvrRpm1 failed to show any RPM1-dependent HR when inoculated into plants (our unpublished observations). This could indicate that the AvrRpt2-AvrRpm1 chimeras cannot localize to the appropriate location in planta as a result of the lack of a myristoylation site in the AvrRpt2-AvrRpm1 chimera. Further studies of the in planta locations of AvrRpt2 and the various chimeras will clarify the role of membrane localization in AvrRpt2 function.

In summary, the use of single-copy expression of avrRpt 2 has provided new insights into virulence and a transmission function for AvrRpt2. Additionally, it allowed for the rapid construction and analysis of altered versions of AvrRpt 2 for the functional dissection of the protein modules. The quantitative difference in phenotypes between strains carrying avr genes on plasmids and those harboring single-copy integrations suggests that care should be taken when examining effector functions with the use of genes on multicopy plasmids.

\section{MATERIALS AND METHODS}

\section{Bacterial strains, media. and plasmids.}

Bacterial strains and plasmids used in this study are listed in Table 1. P. syringae strain PsmES4326 was obtained from F. M. Ausubel (Massachusetts General Hospital and Harvard University, Boston, MA, U.S.A.). Escherichia coli strains were grown in Luria-Bertani or SOC medium (Sambrook et al. 1989) in a tube roller at $37^{\circ} \mathrm{C}$. P. syringae strains were grown in King's B (KB) medium (King et al. 1954) or SOC in a tube roller at $30^{\circ} \mathrm{C}$. Where specified, kanamycin $(\mathrm{Km})$, streptomycin (Str), tetracycline (Tet), ampicillin (Amp), and cycloheximide $(\mathrm{CH})$ were added to the liquid media and plates in the following concentrations per ml: $50 \mu \mathrm{g}$ of $\mathrm{Km}, 100 \mu \mathrm{g}$ of Str, $25 \mu \mathrm{g}$ of Tet, $100 \mu \mathrm{g}$ of Amp, and $50 \mu \mathrm{g}$ of CH. Strains harboring vector-borne avrRpt2 or avrRpml carried these genes on derivatives of pLAFR (plasmid pLH12) (Whalen et al. 1991) and pK48 (Dangl et al. 1992), respectively.

\section{Plant lines and growth conditions.}

Plants (Arabidopsis thaliana) were grown in growth chambers under long-day conditions (cycle $=16 \mathrm{~h}$ of light, $8 \mathrm{~h}$ of dark), as described in Greenberg et al. (2000). All assays were performed with Arabidopsis spp. ecotype Columbia, unless indicated otherwise. Arabidopsis spp. rps2-101c (ecotype Columbia) was provided by F. M. Ausubel. Ecotype HS12 (rpm1-RPS2) was provided by R. Mauricio (University of Georgia, Athens, GA, U.S.A.).

\section{Strain construction.}

All polymerase chain reaction (PCR) amplifications were performed with Turbo PFU (Stratagene, La Jolla, CA, U.S.A.), following the manufacturer's recommendations. Table 2 provides primer sequences. PCR products and vectors were cleaned with QIAquick PCR purification columns (Qiagen, Chatsworth, CA, U.S.A.) prior to and following all enzymatic steps. Restriction and modification enzymes were purchased from New England Biolabs (Beverly, MA, U.S.A.). All of the integration vectors were derived from pBluescript $\mathrm{SK}+$ (Stratagene). A $\operatorname{trp} A$ terminator was constructed out of two oligonucleotides (trpAterm+ and trpAterm-) and cloned between the NotI and $\mathrm{XbaI}$ sites of pBluescript to create vector pBCT. Neomycin phosphotransferase (nptII, conferring resistance to $\mathrm{Km}$ and neomycin) was PCR amplified from pZERO2.1 (Invitrogen, San Diego, CA, U.S.A.) with npt+ and npt- primers and cloned into the AseI site of pBCT to create vector pCKT. A 527-bp internal fragment of the recA gene was amplified from PsmES4326 with recA+271 and recA-797 and cloned into the ApaI site of pCKT to create vector pCKTR. avrRpt 2 was PCR amplified from $\mathrm{pLH} 12$. The promoter and full coding sequence were amplified with primers avrRpt2+4 and avrRpt2-1,146. Other primers used and notes regarding the constructs they were used for are presented in Table 2. All constructs are available upon request from D. S. Guttman or J. T. Greenberg. Southern blots were performed following Sambrook et al. (1989).

Avr chimeras were created by SapI seamless cloning. PCR primers extending from the ends of fragments to be cloned in

Table 1. Bacteria and plasmids used in this work

\begin{tabular}{|c|c|c|}
\hline Strain/plasmid & Characteristics $^{\mathrm{a}}$ & Reference/source \\
\hline \multicolumn{3}{|c|}{ Pseudomonas syringae pv. maculicola } \\
\hline PsmES4326 & $\operatorname{Str}^{\mathrm{r}}$ & F. M. Ausubel \\
\hline PsmDG3 & Str $^{\mathrm{r}}$ PsmES4326 recA integration of pCKTR & This study \\
\hline PsmDG6 & Str ${ }^{\mathrm{r}}$ PsmES4326 recA integration of pDSG6 & This study \\
\hline PsmDG7 & $\mathrm{Str}^{\mathrm{r}}$ PsmES4326 recA integration of pDSG7 & This study \\
\hline PsmDG8 & $\mathrm{Str}^{\mathrm{r}}$ PsmES4326 recA integration of pDSG8 & This study \\
\hline PsmDG9 & Str $^{\mathrm{r}}$ PsmES4326 recA integration of pDSG9 & This study \\
\hline PsmDG34 & Str $^{\mathrm{r}}$ PsmES4326 recA integration of pDSG34 & This study \\
\hline \multicolumn{3}{|l|}{ Plasmids } \\
\hline pLAFR3 & Tet $^{\mathrm{r}}$ broad-host-range vector & Staskawicz et al. 1987 \\
\hline pLH12 & Tet $^{\mathrm{r}}$ pLAFR 3 containing avrRpt 2 & Whalen et al. 1991 \\
\hline pK48 & Tet $^{\mathrm{r}}$ pLAFR 5 containing avrRpm 1 & Debener et al. 1991 \\
\hline $\mathrm{pBC}$ & $\mathrm{Cm}^{\mathrm{r}}$ cloning phagemid & Stratagene, La Jolla, CA, U.S.A. \\
\hline pCKTR & $\begin{array}{l}\mathrm{Km}^{\mathrm{r}} \mathrm{pBluescript} \text { derivative contains } n p t I I \text { and a 527-bp internal recA } \\
\text { fragment from PsmES4326 }\end{array}$ & This study \\
\hline pDSG6 & pCKTR containing avrRpt2 (including native promoter) & This study \\
\hline pDSG7 & pCKTR containing $\operatorname{avrRpm1}($ pro +43 aa)::avrRpt2 $(\Delta 41$ aa $)$ & This study \\
\hline pDSG8 & pCKTR containing $\operatorname{avrRpml}($ pro +43 aa)::avrRpt2 $(\Delta 79$ aa) & This study \\
\hline pDSG9 & pCKTR containing avrRpml(pro +89 saa)::avrRpt2 ( $\Delta 41$ aa) & This study \\
\hline pDSG34 & pCKTR containing avrRpml & This study \\
\hline
\end{tabular}

${ }^{\mathrm{a}}$ pro $=$ promoter of the respective gene; $\mathrm{aa}=$ amino acid . 
the chimeric fusion junction had a $5^{\prime}$ extension that included the recognition sequence for the restriction enzyme SapI, which cuts downstream from its recognition sequence and leaves cohesive ends that can be specified during primer design. PCR products were amplified with Turbo PFU, cut with SapI, and ligated, diluted, and reamplified with the two primers that would amplify the entire chimeric gene. These products were then cloned into pCKTR.

Some chimeric gene constructs and deletions were made by "round the vector" (RV) cloning. In this strategy, the locus or loci of interest were individually cloned into pCKTR. PCR primers were then designed to amplify away from each other (pointing out toward the vector), with their $5^{\prime}$ ends corresponding to the desired fusion junctions. Turbo PFU PCR reactions were carried out to amplify the entire vector (approximately 4 to $7 \mathrm{~kb}$ in length, depending on the particular construct). This product was phosphorylated with polynucleotide kinase (PNK; New England Biolabs) and religated. Each construct was sequenced to ensure the integrity of the fusion junction and to control for mutations that could arise during the PCR reactions.

\section{Vector integration and bacteria mating.}

Vectors were electroporated into $P$. syringae at a capacitance of $3 \mu \mathrm{F}$, resistance of $500 \mathrm{ohms}$, and voltage of $2.5 \mathrm{kV}$. Approximately $10 \mathrm{ng}$ of vector was used for each $40 \mu \mathrm{l}$ of electrocompetent cells. Transformed bacteria were grown in $1 \mathrm{ml}$ of $\mathrm{SOC}$ at $30^{\circ} \mathrm{C}$ for $1 \mathrm{~h}$ and pelleted at $5 \mathrm{~K}$ for $5 \mathrm{~min}$. The entire pelleted culture was resuspended in approximately $100 \mu \mathrm{l}$ of media, spread onto KB Km plates, and grown at $30^{\circ} \mathrm{C}$. Positive colonies typically appeared within 3 days. Integration at recA was verified by Southern blot analysis and sensitivity to shortwave UV. rec $A^{-} P$. syringae were three orders of magnitude more sensitive to UV irradiation than the parent strain.

\section{HR, disease assay, and in vivo growth assay.}

For plant inoculation studies, $P$. syringae were grown to saturation in $\mathrm{KB}$, diluted, regrown to $\mathrm{OD}_{600}$ at 0.5 to 1.0 , centrifuged, and resuspended in $10 \mathrm{mM} \mathrm{MgSO}_{4}$ to a concentration of $\mathrm{OD}_{600}$ at 1.0 prior to dilution for plant inoculations. All inoculations were performed with a blunt 1-ml syringe, as described previously (Greenberg et al. 2000). For the HR assay, bacteria were diluted in $10 \mathrm{mM} \mathrm{MgSO}_{4}$ to a range of $\mathrm{OD}_{600}$ at 0.01 to 0.1 and inoculated into leaves from unbolted long-day-grown plants. Plants were left open in the growth chambers and scored for HR symptoms or water soaking and yellowing (disease symptoms) after 18 to $24 \mathrm{~h}$. For conductivity measurements to quantitate the strength of the HR, leaf punches $\left(6 \mathrm{~mm}\right.$ in diameter) were placed in $1 \mathrm{ml}$ of $\mathrm{ddH}_{2} 0$ with the abaxial side toward the solution for $1 \mathrm{~h}$. Conductivity measurements of the solutions were measured with a model CDM2a conductivity meter (Radiometer Copenhagen, Brønshøj, Denmark). To assess the severity of disease symptoms, leaves were first photographed and scanned by a ScanMaker 4 (Microtek, San Francisco, CA, U.S.A.) with Photoshop LE software (Adobe, San Jose, CA, U.S.A.). Printouts of the scanned images of each leaf were cut to separate the fully green portion from the yellowed portion. Each of these portions was subsequently weighed to determine the percentage of green tissue.

For standard in vivo growth assays, bacteria were diluted to $\mathrm{OD}_{600}$ at 0.002 and inoculated in young leaves approximately $1 \mathrm{~cm}$ in length. The leaves were allowed to dry for $2 \mathrm{~h}$ and then tightly covered with a plastic lid to maintain high relative humidity (Rate et al. 1999). Leaf punches (6 $\mathrm{mm}$ in diameter) were surface sterilized in $70 \%$ ethyl alcohol for $1 \mathrm{~min}$, homogenized for $3 \mathrm{~s}$ in $200 \mu \mathrm{l}$ of $10 \mathrm{mM} \mathrm{MgSO}_{4}$ with the use of a plastic disposable pestle and a 3/8-in. power drill (Skil, Chicago, IL, U.S.A.) set at low speed, diluted in $10 \mathrm{mM} \mathrm{MgSO}_{4}$, and plated on KB-glycerol agar plates containing $\mathrm{Km}$.

For the virulence assays, rps 2 plants were inoculated with $P$. syringae at $\mathrm{OD}_{600}$ at 0.0002 . The plants were then washed thoroughly with water to remove bacteria adhering to the surface, allowed to dry in the open for $2 \mathrm{~h}$, and covered with a plastic dome. Whole leaves of similar age and approximately 2 to $3 \mathrm{~cm}$ in length were collected daily from day 0 through 6 (excluding day 5) in $500 \mu \mathrm{l}$ of $10 \mathrm{mM} \mathrm{MgSO}_{4}$ and vortexed to remove surface bacteria. Dilutions of this surface wash were plated on KB-glycerol plates containing $\mathrm{Km}$, Str, and $\mathrm{CH}$. The washed leaves were assayed for bacteria, as described above.

Table 2. Polymerase chain reaction (PCR) primers used in the work

\begin{tabular}{|c|c|c|}
\hline PCR primer & Primer sequence $^{a}$ & Notes $^{b}$ \\
\hline $\begin{array}{l}\text { npt }^{+} \\
\text {npt }^{-} \\
\text {recA }+271 \\
\text { recA }-797 \\
\text { trpAterm } \\
\text { trpAterm } \\
\text { avrRpt2+4 } \\
\text { avrRpt2-1146 } \\
\text { avrRpm1 } 1 \text { 5p190 } \\
\text { avrRpm1-3p660 }\end{array}$ & $\begin{array}{l}\text { GGTCTGACGCTCAGTGGAACGAAAAC } \\
\text { TCCAAACTGGAACAACACTCAACCC } \\
\text { TTCGTCGACGCCGAGCACGC } \\
\text { CCCTTGCCGTAGAGGATCTGGAACTC } \\
\text { CAGCCCGCCTAATGAGCGGGCTTTTTTTGC } \\
\text { GGCCGCAAAAAAAAGCCCGCTCATTAGGCGGGCTGAGCA } \\
\text { GATTGATCTCTGGCTCAGTGCG } \\
\text { TGGCAGATGCTCATGGACAAGCG } \\
\text { GAATTCGGCAAAAATCGTACGCAG } \\
\text { AAAGTCATCTTCTGAGTCAGACTGAACAGC }\end{array}$ & $\begin{array}{l}\text { avrRpt2 } 5^{\prime} \text { primer } \\
\text { avrRpt2 } 3^{\prime} \text { primer } \\
\text { avrRpm1 } 5^{\prime} \text { primer } \\
\text { avrRpm1 } 3 \text { ' primer }\end{array}$ \\
\hline $\begin{array}{l}\text { Primers used for avrRp } \\
\text { cloning } \\
\text { avrRpt2 }+296 \mathrm{sap} \\
\text { avrRpt2 + 409sap } \\
\text { avrRpm1 - 135sap } \\
\text { avrRpm1 - 268sap }\end{array}$ & $\begin{array}{l}\text { (GATGCTCTTCAGGG)AAAAGTAGCGCTTCAAGCCCG } \\
\text { (GATGCTCTTCAGGG)AAGCACGAGACGGGCGGTTCAAGTG } \\
\text { (GATGCTCTTCACCC)ATTGGAATGCTCGGAATCGGTTTC } \\
\text { (GATGCTCTTCACCC)CTCGGTTGCACCATCAGTTTTTC }\end{array}$ & $\begin{array}{l}41 \text { aa } \mathrm{N} \text {-terminus deleted } \\
79 \text { aa } \mathrm{N} \text {-terminus deleted } \\
\mathrm{N} \text {-terminus } 45 \text { aa } \\
\text { N-terminus } 89 \text { aa }\end{array}$ \\
\hline
\end{tabular}

${ }^{a}$ Parenthetical segment used for SapI seamless cloning.

$\mathrm{b}$ aa $=$ amino acid. 


\section{Protein extraction and immunoblot assay.}

$P$. syringae strains were grown in M9 minimal media (Sambrook et al. 1989) with sucrose to an $\mathrm{OD}_{600}$ at 1.0. One milliliter of cells were pelleted, resuspended in $50 \mu \mathrm{l}$ of alkaline lysis miniprep solution 1 (Sambrook et al. 1989), $50 \mu \mathrm{l}$ of $2.22 \times$ denaturing sample buffer (125 mM Tris, $\mathrm{pH} 6.8 ; 20 \%$ glycerol; $4 \%$ sodium dodecyl sulfate [SDS]; $5 \mathrm{M}$ urea; $0.01 \%$ bromophenol blue), and $10 \mu \mathrm{l}$ of $1 \mathrm{M}$ dithiothreitol, and heated to $95^{\circ} \mathrm{C}$ for $5 \mathrm{~min}$. Protein samples were electrophoresed on SDS-polyacrylamide slab gel electrophoresis in Tris-glycine running buffer (1.9 $\mathrm{M}$ glycine; $250 \mathrm{mM}$ Tris-base $0.1 \%$ SDS, $\mathrm{pH} 8.8$ ) and transferred to a Millipore Immobilon-P membrane by semidry blotting in transfer buffer $(1.9 \mathrm{M}$ glycine, $250 \mathrm{mM}$ Tris-base, $10 \%$ methanol). Membranes were blocked in BLOTTO (Sambrook et al. 1989) and incubated overnight at $4^{\circ} \mathrm{C}$ in $1: 10,000$ anti-AvrRpt2. Donkey anti-rabbit secondary antibody was used at 1:5,000 after four room-temperature washes in BLOTTO. Detection was carried out in Supersignal West Pico developing reagent (Pierce, Rockford, IL, U.S.A.) for 1 to $30 \mathrm{~s}$.

\section{Statistical analysis.}

All statistical analyses were performed with StatView for Windows or Macintosh version 5.0.1 (SAS Institute, Cary NC, U.S.A.).

\section{ACKNOWLEDGMENTS}

We thank B. Kunkel for antiserum against AvrRpt2 and for communicating unpublished results. We thank A. Driks, B. Kunkel, B. A. Vinatzer, and J. Mach for helpful discussions and comments on the manuscript. D. S. Guttman was supported by an individual NSRA grant from the National Institutes of Health (5 F32 GM20024-02). J. T. Greenberg is a Pew scholar. This research was supported by a grant to $\mathrm{J}$. T. Greenberg from the Consortium for Plant Biotechnology Research and by an award to the University of Chicago's Division of Biological Sciences under the Research Resources Program for Medical Schools of the Howard Hughes Medical Institute.

\section{LITERATURE CITED}

Abebe, H. M., Seidler, R. J., Lindow, S. E., Short, K. A., Clark, E., and King, R. J. 1997. Relative expression and stability of a chromosomally integrated and plasmid-borne marker gene fusion in environmentally competent bacteria. Curr. Microbiol. 34:71-78.

Alfano, J. R., and Collmer, A. 1997. The type III (Hrp) secretion pathway of plant pathogenic bacteria: Trafficking harpins, Avr proteins, and death. J. Bacteriol. 179:5655-5662.

Anderson, D., and Schneewind, O. 1997. A mRNA signal for the type III secretion of Yop proteins by Yersinia enterocolitica. Science 278:1140-1143.

Anderson, D. M., Fouts, D. E., Collmer, A., and Schneewind, O. 1999. Reciprocal secretion of proteins by the bacterial type III machines of plant and animal pathogens suggests universal recognition of Mrna targeting signals. Proc. Natl. Acad. Sci. USA 96:12839-12843.

Bonas, U., and Van den Ackerveken, G. 1999. Gene-for-gene interactions: Bacterial avirulence proteins specify plant disease resistance. Curr. Opin. Microbiol. 2:94-98.

Chen, Z., Kloek, A. P., Boch, J., Katagiri, F., and Kunkel, B. N. 2000. The Pseudomonas syringae avrRpt 2 gene product promotes pathogen virulence from inside plant cells. Mol. Plant-Microbe Interact. 13:1312-1321.

Cheng, L. W., Anderson, D. M., and Schneewind, O. 1997. Two independent type III secretion mechanisms for YopE in Yersinia enterocolitica. Mol. Microbiol. 24:757-765.

Dang1, J. L., Ritter, C., Gibbon, M. J., Mur, L. A., Wood, J. R., Goss, S., Mansfield, J., Taylor, J. D., and Vivian, A. 1992. Functional homologs of the Arabidopsis RPM1 disease resistance gene in bean and pea. Plant Cell 4:1359-1369.

Debener, T., Lehnackers, H., Arnold, M., and Dangl, J. L. 1991. Identification and molecular mapping of a single Arabidopsis thaliana locus determining resistance to a phytopathogenic Pseudomonas syringae isolate. Plant J. 1:289-302.

De Feyter, R., McFadden, H., and Dennis, L. 1998. Five avirulence genes from Xanthomonas campestris pv. malvacearum cause genotype-specific cell death when expressed transiently in cotton. Mol. Plant-Microbe Interact. 11:698-701.

Dong, X., Mindrinos, M., Davis, K. R., and Ausubel, F. M. 1991. Induction of Arabidopsis defense genes by virulent and avirulent Pseudomonas syringae strains and by a cloned avirulence gene. Plant Cell 3:61-72.

Fenselau, S., Balbo, I., and Bonas, U. 1992. Determinants of pathogenicity in Xanthomonas campestris pv. vesicatoria are related to proteins involved in secretion in bacterial pathogens of animals. Mol. Plant-Microbe Interact. 5:390-396.

Gabriel, D. W. 1999. Why do pathogens carry avirulence genes? Physiol. Mol. Plant Pathol. 55:205-214.

Gopalan, S., Bauer, D. W., Alfano, J. R., Loniello, A. O., He, S. Y., and Collmer, A. 1996. Expression of the Pseudomonas syringae avirulence protein AvrB in plant cells alleviates its dependence on the hypersensitive response and pathogenicity (Hrp) secretion system in eliciting genotype-specific hypersensitive cell death. Plant Cell 8:1095-1105.

Gough, C. L., Genin, S., Zischek, C., and Boucher, C. A. 1992. hrp genes of Pseudomonas solanacearum are homologous to pathogenicity determinants of animal pathogenic bacteria and are conserved among plant pathogenic bacteria. Mol. Plant-Microbe Interact. 5:384389.

Greenberg, J. T. 1997. Programmed cell death in plant-pathogen interactions. Annu. Rev. Plant Physiol. Plant Mol. Biol. 48:525-545.

Greenberg, J. T., Silverman, F. P., and Liang, H. 2000. Uncoupling salicylic acid-dependent cell death and defense-related responses from disease resistance in the Arabidopsis mutant acd5. Genetics 156:341350 .

Hendrickson, E., Guevera, P., and Ausubel, F. 2000. The alternative sigma actor RpoN is required for hrp activity in Pseudomonas syringae pv. maculicola and acts at the level of hrpL transcription. J. Bacteriol. 182:3508-3516.

Innes, R. W., Bent, A. F., Kunkel, B. N., Bisgrove, S. R., and Staskawicz, B. J. 1993. Molecular analysis of avirulence gene avrRpt 2 and identification of a putative regulatory sequence common to all known Pseudomonas syringae avirulence genes. J. Bacteriol. 175:4859-4869.

Jackson, R. W., Athanassopoulos, E., Tsiamis, G., Mansfield, J. W., Sesma, A., Arnold, D. L., Gibbon, M. J., Murillo, J., Taylor, J. D., and Vivian, A. 1999. Identification of a pathogenicity island, which contains genes for virulence and avirulence, on a large native plasmid in the bean pathogen Pseudomonas syringae pathovar phaseolicola. Proc. Natl. Acad. Sci. USA 96:10875-10880.

Kearney, B., and Staskawicz, B. J. 1990. Widespread distribution and fitness contribution of Xanthomonas campestris avirulence gene avrBs2. Nature 346:385-386.

King, E. O., Ward, M. K., and Raney, D. E. 1954. Two simple media for the demonstration of pyocyanin and fluorescin. J. Lab. Clin. Med. 44:201-207.

Leister, R. T., Ausubel, F. M., and Katagiri, F. 1996. Molecular recognition of pathogen attack occurs inside of plant cells in plant disease resistance specified by the Arabidopsis genes RPS2 and RPM1. Proc. Natl. Acad. Sci. USA 93:15497-15502.

Mudgett, M. B., and Staskawicz, B. J. 1999. Characterization of the Pseudomonas syringae pv. tomato AvrRpt2 protein: Demonstration of secretion and processing during bacterial pathogenesis. Mol. Microbiol. 32:927-941.

Nimchuk, Z., Marois, E., Kjemtrup, S., Leister, R. T., Katagiri, F., and Dangl, J. L. 2000. Eukaryotic fatty acylation drives plasma membrane targeting and enhances function of several type III effector proteins from Pseudomonas syringae. Cell 101:353-363.

Pirhonen, M. U., Lidell, M. C., Rowley, D. L., Lee, S. W., Jin, S., Liang, Y., Silverstone, S., Keen, N. T., and Hutcheson, S. W. 1996. Phenotypic expression of Pseudomonas syringae avr genes in E. coli is linked to the activities of the hrp-encoded secretion system. Mol. 
Plant-Microbe Interact. 9:252-260.

Rate, D. N., Cuenca, J. V., Bowman, G. R., Guttman, D. S., and Greenberg, J. T. 1999. The gain-of-function Arabidopsis acd6 mutant reveals novel regulation and function of the salicylic acid signaling pathway in controlling cell death, defenses, and cell growth. Plant Cell 11:1695-1708.

Ritter, C., and Dangl, J. L. 1995. The avrRpml gene of Pseudomonas syringae pv. maculicola is required for virulence on Arabidopsis. Mol. Plant-Microbe. Interact. 8:444-453.

Sambrook, J., Fritsch, E. F., and Maniatis, T. (1989). Molecular Cloning: A Laboratory Manual, 2nd ed. Cold Spring Harbor Laboratory Press, Cold Spring Harbor, NY, U.S.A.

Scofield, S. R., Tobias, C. M., Rathjen, J. P., Chang, J. H., Lavelle, D. T., Michelmore, R. W., and Staskawicz, B. J. 1996. Molecular basis of gene-for-gene specificity in bacterial speck disease of tomato. Science 274:2063-2065.

Sory, M. P., and Cornelis, G. R. 1994. Translocation of a hybrid YopEadenylate cyclase from Yersinia enterocolitica into HeLa cells. Mol. Microbiol. 14:583-594.

Sory, M. P., Boland, A., Lambermont, I., and Cornelis, G. R. 1995. Identification of the YopE and YopH domains required for secretion and internalization into the cytosol of macrophages, using the cyaA gene fusion approach. Proc. Natl. Acad. Sci. USA 92:11998-12002.

Staskawicz, B., Dahlbeck, D., Keen, N., and Napoli, C. 1987. Molecular characterization of cloned avirulence genes from race- 0 and race- 1 of Pseudomonas syringae pv. glycinea. J. Bacteriol 169:5789-5794.

Stevens, C., Bennett, M. A., Athanassopoulos, E., Tsiamis, G., Taylor, J. D., and Mansfield, J. W. 1998. Sequence variations in alleles of the avirulence gene avrPphE.R2 from Pseudomonas syringae pv. phaseolicola lead to loss of recognition of the AvrPphE protein within bean cells and a gain in cultivar-specific virulence. Mol. Microbiol. 29:165-177.

Tang, X., Frederick, R. D., Zhou, J., Halterman, D. A., Jia, Y., and
Martin, G. B. 1996. initiation of plant disease resistance by physical interaction of Avrpto and Pto kinase. Science 274:2060-2063.

Van den Ackerveken, G., Marois, E., and Bonas, U. 1996. Recognition of the bacterial avirulence protein AvrBs3 occurs inside the host plant cell. Cell 87:1307-1316.

Van Gijsegem, F., Genin, S., and Boucher, C. 1993. Conservation of secretion pathways for pathogenicity determinants of plant and animal bacteria. Trends Microbiol. 1:175-180.

Van Gijsegem, F., Arlat, M., Genin, S., Gough, C. L., Zischek, C., Barberis, P. A., and Boucher, C. 1994. Genes governing the secretion of factors involved in host-bacteria interactions are conserved among animals and plant pathogenic bacteria. Molecular Mechanisms of Bacterial Virulence, C. I. Kado and. J. H. Crosa, eds. Kluwer Academic Publishers, Boston.

Van Gijsegem, F., Gough, C., Zischek, C., Niqueux, E., Arlat, M., Genin, S., Barberis, P., German, S., Castello, P., and Boucher, C. 1995. The hrp gene locus of Pseudomonas solanacearum, which controls the production of a type III secretion system, encodes eight proteins related to components of the bacterial flagellar biogenesis complex. Mol. Microbiol. 15:1095-1114.

Whalen, M. C., Innes, R. W., Bent, A. F., and Staskawicz, B. J. 1991 Identification of Pseudomonas syringae pathogens of Arabidopsis and a bacterial locus determining avirulence on both Arabidopsis and soybean. Plant Cell 3:49-59.

Willis, D. K., Hrabak, E. M., Lindow, S. E., and Panopoulos, N. J. 1988 Construction and characterization of Pseudomonas syringae recA mutant strains. Mol. Plant-Microbe Interact. 1:80-86.

Yang, Y., De Feyter, R., and Gabriel, D. W. 1994. Host-specific symptoms and increased release of Xanthomonas citri and X. campestris pv. malvacearum from leaves are determined by the 102-bp tandem repeats of pthA and avrb6, respectively. Mol. Plant-Microbe Interact. 7:345-355. 